\title{
Microsurgical technique in excision of intramedullary craniocervical ependymomas. Video report
}

\author{
Ehab El Refaee, M.D., MSc, ${ }^{1,2}$ Marc Matthes, MSc, ${ }^{1}$ \\ and Henry W. S. Schroeder, M.D., Ph.D. ${ }^{1}$ \\ ${ }^{1}$ Department of Neurosurgery, University Medicine Greifswald, Germany; ${ }^{2}$ Department of Neurosurgery, \\ Cairo University, Egypt
}

We present the microsurgical technique in excision of intramedullary craniocervical ependymomas. A 27-yearold female came presenting with neck pain and parasthesia in her both arms and hands, where MRI was performed showing intramedullary lesion that extend in the medulla just beyond the foramen magnum to the level of C5-6 disc. Tumor was totally excised using irrigation-dissection microscopic technique with favorable outcome.

The video can be found here: http://youtu.be/Yj1yvZOaz58.

(http://thejns.org/doi/abs/10.3171/2014.V3.FOCUS14391)

$\begin{array}{lcll}\text { KEY WoRds } & \bullet \quad \text { intramedullary } \quad \text { ependymomas } \\ \text { medulla } & \bullet & \\ & \text { irrigation-dissection microscopic technique } & \bullet & \text { video }\end{array}$

Manuscript submitted July 1, 2014.

Accepted July 18, 2014.

Please include this information when citing this paper: DOI: 10.3171/2014.V3.FOCUS14391.

Address correspondence to: Ehab E. Refaee, M.D., Ernst Moritz Arndt University, Neurosurgery, Sauerbruchstrasse, Greifswald, D-17487, Germany. email: e.elrefaee@googlemail.com. 